\title{
Modeling of Magnetic Anomaly zones in Sokoto Basin, Nigeria.
}

\author{
Bonde,D. $\mathrm{S}^{* 1}$, Udensi E. E $\mathrm{E}^{2}$.Momoh $\mathrm{M}^{1}$ \\ ${ }^{1}$ Department of physics, Kebbi State University of Science and Technology, Aliero. \\ ${ }^{2}$ Department of physics, Federal University Technology, Minna.
}

\begin{abstract}
D$ modeling of major magnetic anomalies identified in the residual map of Sokoto Basin was carried out with the view to study the basement depth of the basin. The Sokoto Basin is situated between latitudes $10^{\circ} 30^{\prime \prime} \mathrm{N}$ to $14^{\circ} 00^{\prime \prime} \mathrm{N}$ and longitude $3^{\circ} 30^{\prime \prime} \mathrm{E}$ to $7^{\circ} 00^{\prime \prime} \mathrm{E}$ with an estimated area of $59,570 \mathrm{~km}^{2}$. Six profiles are drawn along areas of major magnetic anomalies identified in the residual map. The results of the studies indicate an increase in sedimentation northwards, with several depressions on the basement rock. Several undulations with varying sedimentary thicknesses are observed. The highest sedimentary thickness of $2.7 \mathrm{~km}$ was encountered on sheet No 28 (Argungu).These areas of higher sedimentary thicknesses such as sheets No 28 (Argungu), sheet No.12 (Isah) and sheet No.13 (Gandi) encountered in this study, are the most probable sites for prospect of hydrocarbon accumulation in the basin .

Key words: Modeling; Composite map; residual map, Basement Depth; Anomalies
\end{abstract}

\section{Introduction}

The earth subsurface has been of great concern to geoscientists, who seek to investigate it using diverse means, some for the purpose of having knowledge, while others do it for exploration of economic resources such as minerals and hydrocarbons which lie concealed beneath the earth surface. The presence and magnitude of these resources can only be ascertained by geophysical investigations of the subsurface geologic structures in the area.

Geophysical methods may be applied to a wide range of investigations from studies of the entire Earth to exploration of a localized region of the upper crust for engineering or other purposes (Kearey et al., 2004). A wide range of geophysical methods exist, for each there is an operative physicalproperty to which the method is sensitive. The type of physical property to which a method responds clearly determines its range of a pplication. Thus, for instance, magnetic method very suitable for locating buried magnetic ore bodies, because o ftheir magnetic susceptibility. Similarly, seismic and electrical methods are suitable for locating water table, bec ause saturated rock may be distinguished from dry rock by its higher seismic velocity and higher electrical conductivity (Dobrin 1976).

Geophysical methods are capable of detecting and delineating local features of potential interest. Geophysical methods for detecting discontinuities, faults, joints and other basement structures, include the following: magnetics, seismic, resistivity, electrical, potential field, well logging, gravity, radiometric, thermal etc (Corell andGrauch, 1985) .

Some geophysical methods such as gamma- ray spectrometry and remote sensing measure surface attributes; others, such as thermal and some electrical methods are limited to detecting relatively shallow subsurface geological features. Geophysical modeling provides generalized and no-unique solution to questions concerning the concerning the geometry of the subsurface geologic structures (Reeves, 2005).

If the area to be investigated has no previous geophysical information and the primary aim of the study is to search for hydrocarbon deposits; the first question that must be answered among other necessary conditions for hydrocarbon maturation, is whether the sedimentary basin is large enough and thick enough to justify any further investigations ( Reynolds,1990).

Modeling of aeromagnetic data over the area would differentiate and characterize regions of sedimentary thickening from those uplifted or shallow basement areas and also determine the depths to the magnetic sources. The results could be used to suggest whether or not the study area has the potential for oil /gas and mineral deposits concentration.

Exploration of the Nigerian inland basins is worth given a push. Hydrocarbons if discovered and harnessed finds will increase the country's reserve and boost productivity. All these will have economic and strategic benefits for the country.

In this study, observed anomaly zones in the residual map of the Sokoto Basin was modeled to determine the Sedimentary thicknesses in parts of the Basin. 
Modeling of Magnetic Anomaly zones in Sokoto Basin, Nigeria.

\subsection{Data Acquisition}

\section{Materials And Methods}

The study area (Sokoto Sedimentary Basin) is covered by twenty nine aeromagnetic maps of total field intensity in half -degree sheets(NGSA,1976). These maps are obtained from the Nigerian Geological Survey Agency (NGSA), now renamed the Nigerian Geological Survey Agency (NGSA)). The Agency carried out an airborne magnetic survey of substantial part of Nigeria between 1974 and 1980. The magnetic information consists of flight lines plotted on a continuous strip chart or tape records. The data were collected at a nominal flight altitude of $152.4 \mathrm{~m}$ along $\mathrm{N}-\mathrm{S}$ flight lines spaced approximately $2 \mathrm{~km}$ apart. The magnetic data collected were published in the form $1 / 2$ degree aeromagnetic maps on a scale of $1: 100,000$. The magnetic values were plotted at $10 \mathrm{Nt}$ (nanoTesla) interval. The maps are numbered, and names of places and coordinates (longitude and latitudes) written for easy reference and identification. The actual magnetic values were reduced by 25,000 gamma before plotting the contour map. This implies that the value 25,000 gamma is to be added to the contour values so as to obtain the actual magnetic field at a given point. A correction based on the International Geomagnetic Reference Field, (IGRF,) and epoch date January 1, 1974 was included in all the maps.

The visual interpolation method, that is the method of digitizing on Grid Layout was used to obtain the data from twenty nine aeromagnetic maps covering the study area. The data from each digitized map is recorded in a 19 by 19 coding sheet which contains the longitude, latitude and the name of the town flown and the sheet number. The unified composite dataset for the study area was produced after removing the edge effect. Surfer 8 was used to import the dataset. The dataset consists of three columns (longitude,latitude and magnetic values). The composite map was produced using Oasis Montaj .

\subsection{Regional-residual Separation}

Magnetic data observed in geophysical surveys comprises of the sum of all magnetic fields produced by all underground sources(Spector ,1968). The composite map produced, therefore contains two important disturbances, which are different in order of sizes and generally super-imposed.The large features generally show up as trends, which continue smoothly over a considerable distance. These trends are known as regional trends. Super-imposed on the regional field, but frequently camouflaged by these, is the smaller, local disturbances which are secondary in size but primary in importance. These are the residual anomalies which may provide direct evidence of the existence of the reservoir type structures or mineral ore bodies.

\subsection{Production of Regional and Residual Maps}

The residual magnetic field of the study area was produced by subtracting the regional field from the total magnetic field using the Polynomial fitting method. The computer program Aerosupermap was used to generate the coordinates of the total intensity field data values. This super data file, for all the magnetic values was used for production of composite aeromagnetic map of the study area using Oasis Montaj. A program was used to derive the residual magnetic values by subtracting values of regional field from the total magnetic field values to produce the residual magnetic map and the regional map.

\subsection{Modeling of the Residual Map}

The main purpose of magnetic survey is to detect bodies possessing unusual magnetic properties, which reveal themselves by causing anomalies in the earth's magnetic field. In surveys of sedimentary basins such as this, the strongest anomalies are due to lithological contrasts within the basement, because sedimentary rocks are non magnetic such that any magnetic anomaly must originate from within the igneous crystalline basement complex. Modeling techniques involves making numerical estimates of the depth and dimensions of the sources of anomalies and this often takes the form of modeling of sources which could, in theory replicate the anomalies recorded in the survey. The technique applied in any survey depends on the structures intended to be modeled and the purpose of the survey.

In this work, some outstanding anomalies in the residual magnetic intensity map of the study area was used as guide in choosing the modeling profiles.

\subsection{Total Magnetic Intensity Map.}

\section{Results and Discussions}

The total magnetic intensity map (TMI) of the Sokoto sedimentary basin produced from this study using Oasis Montaj is as shown in Figure 1. The TMI map of Sokoto sedimentary basin can be divided into main three sections, though minor depressions exist scattered all over area. The northern part of the Sokoto basin is characterized by low magnetic intensity values represented by dark-green-blue color. Whereas the southern part is dominated by high magnetic intensity values indicated by red color. The two sections are separated by a zone characterized by medium magnetic intensity values area depicted by yellow-orange color. These high magnetic intensity values, which dominate the southern part of the Sedimentary basin are caused probably by near 
surface igneous rocks of high values of magnetic susceptibilities. The low amplitudes are most likely due to sedimentary rocks and other non-magnetic sources. In general, high magnetic values arise from igneous and crystalline basement rocks. Whereas low magnetic values are usually from sedimentary rocks or altered basement rocks. The sedimentary thickness of the Sokoto basin in general, appears to increases from south to north. This collaborates well with earlier findings of 2D Seismic surveys conducted by ELF and Mobil Companies carried out in 1979.

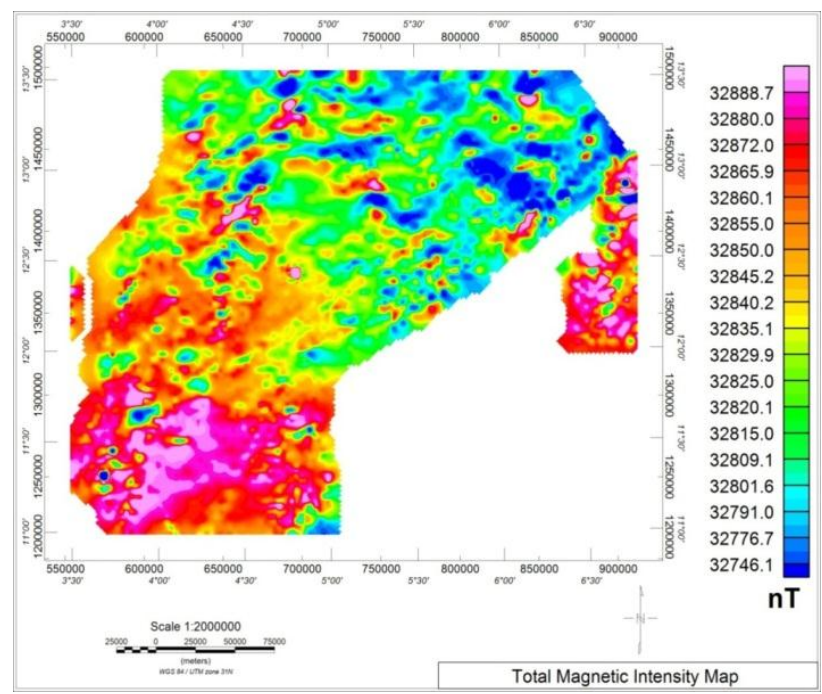

Figure 1 Total magnetic intensity map of the study area.

\subsection{Regional Magnetic Intensity Map.}

The regional magnetic intensity map of the study area (Figure 2) produced using Oasis Montaj.

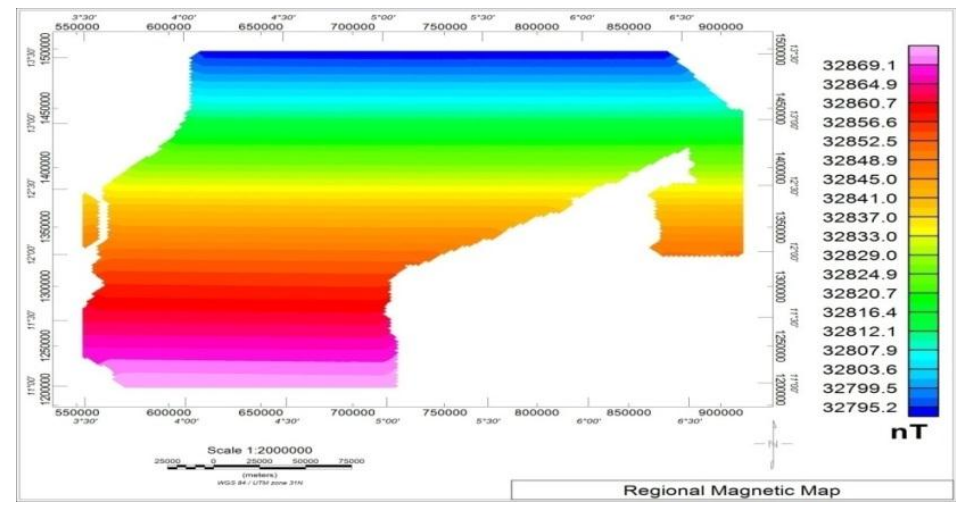

Figure 2 Regional Map of the Study Are

The regional magnetic values ranges from 7830 nano tesla to 7870 nano tesla and the values decreases from south to north indicating there is a fill of sediments more in the northern part of the basin than in the southern part of the study area

\subsection{Residual Magnetic Intensity Map.}

Figure 3 and Figure 4 are the residual magnetic intensity maps of the study area obtained from the total magnetic intensity map produced using Surfer 8 and Oasis Montaj version 7.2 respectively.The magnetic intensity values ranges from -10 nano tesla to 40 nano tesla. Negative magnetic intensity values are more predominant in the northern section of the study area while the southwest has more of positive magnetic intensity values. Northeast -Southwest trends are observed in the north central part of the TMI map. 

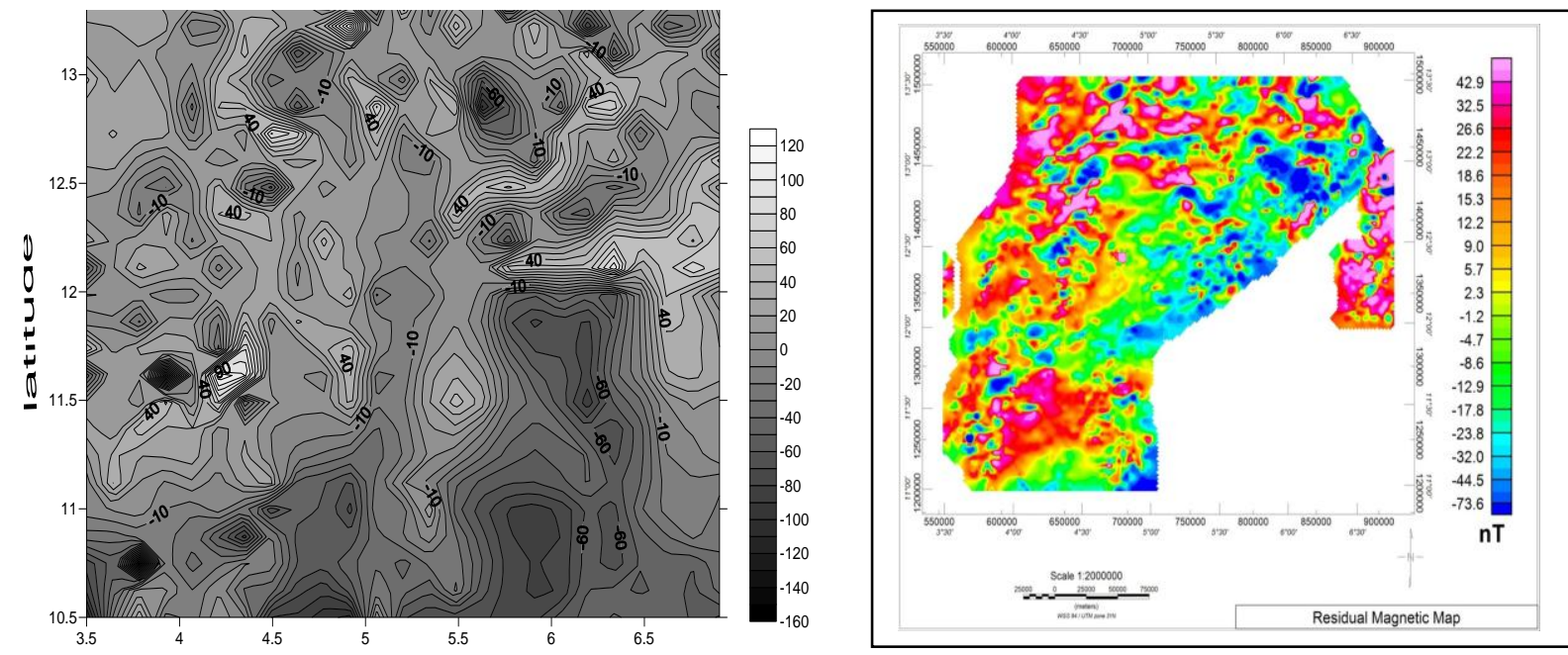

longitude

Figure 4 Residual Magnetic Intensity Map of the study area. Figure 3 Residual Magnetic Intensity Map of the study area.

\subsection{Profile modeling}

The six profiles $\mathrm{SXY}^{1}, \mathrm{SXY}^{2}, \mathrm{SXY}^{3}, \mathrm{SXY}^{4} \mathrm{SXY}^{5}$ and $\mathrm{SXY}^{6}$ were drawn on the residual anomaly map. These profiles were drawn across the residual magnetic map super impose on the geology.The profiles were drawn perpendicular to features identified and selected anomalies.

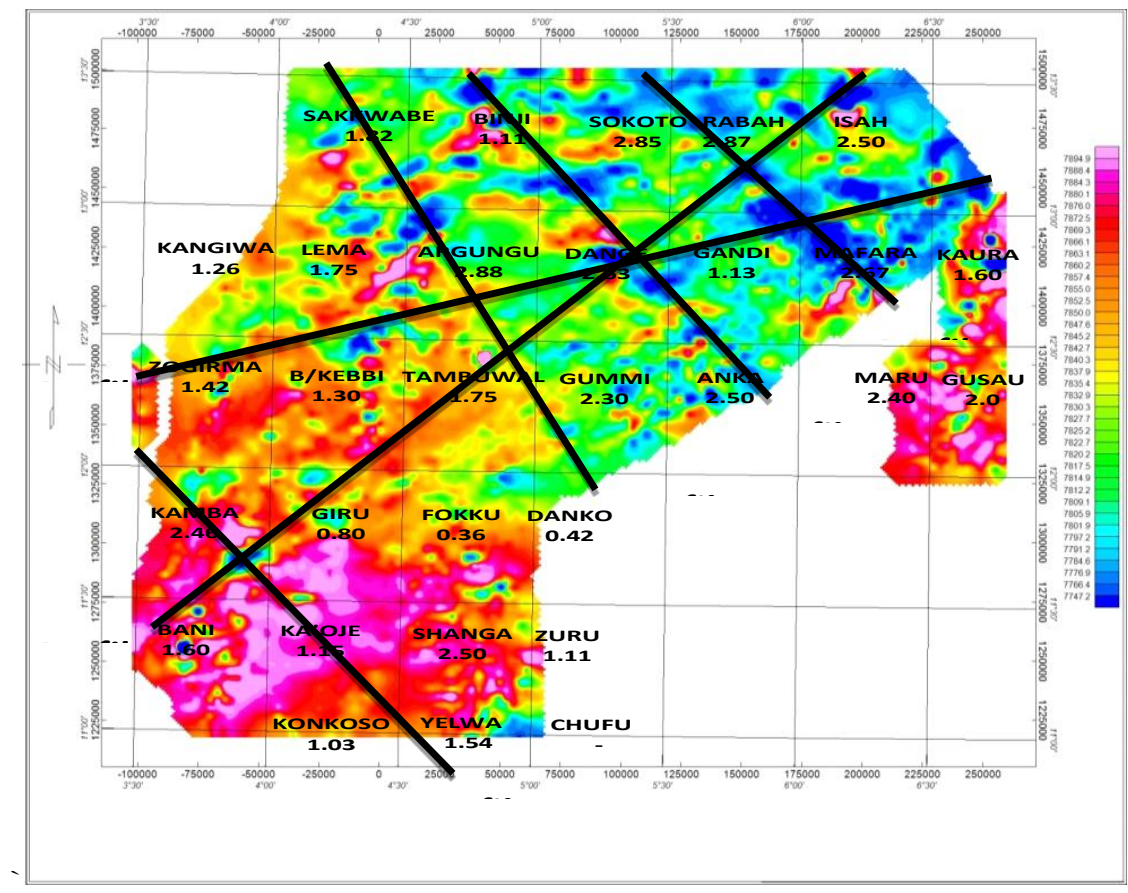

Figure 8 Residual Map Showing the model profiles 

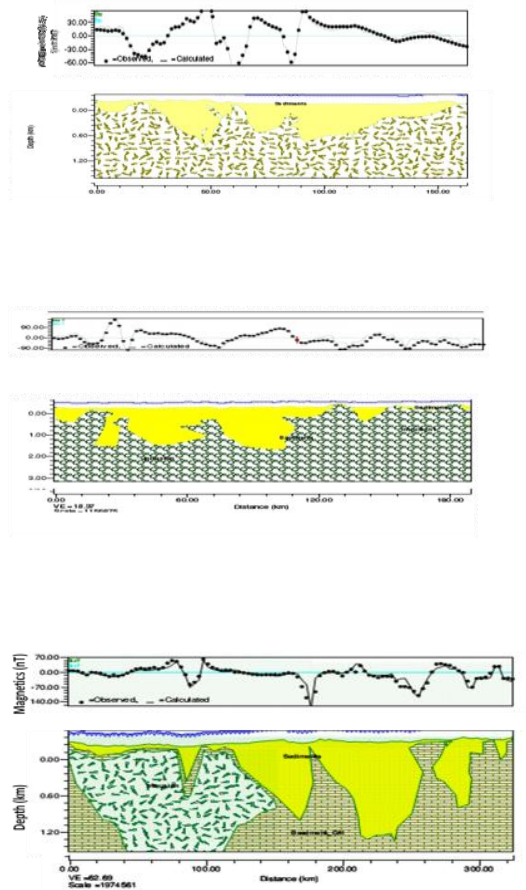

Basement

If Intrusion

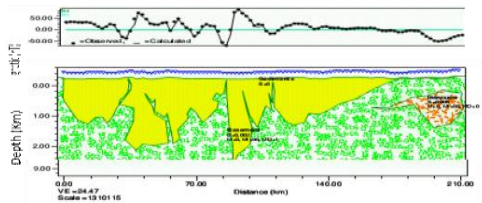

量部

两
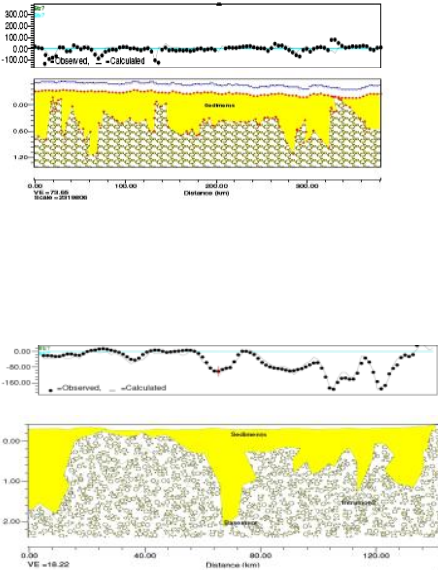

In this research work, Oasis Montaj was used to model anomalous bodies highlited in the residual magnetic intensity map. The models obtained for the six profiles are presented and discussed below.

\begin{tabular}{|l|l|l|l|l|}
\hline PROFILE NO. & DIRECTION & $\begin{array}{l}\text { APROX. } \\
\text { LENGTH(km) }\end{array}$ & $\begin{array}{l}\text { TRAVEVERSE } \\
\text { SHEETS }\end{array}$ & $\begin{array}{l}\text { MAX. } \\
\text { DEPTH(km) }\end{array}$ \\
\hline PROFILE 1 & SW-NE & 200 & $48,72,96$. & 1.67 \\
\hline PROFILE 2 & SW-NE & 210 & $\mathbf{8 , 2 8 , 5 0 , 5 1}$ & $\mathbf{2 . 7 0}$ \\
\hline PROFILE 3 & SW-NE & 180 & $\mathbf{9 , 1 0 , 2 9 , 5 2}$. & 1.6 \\
\hline PROFILE 4 & SW-NE & 240 & Rabah,gandi,mafara & 2.5 \\
\hline PROFILE 5 & NW-SE & 300 & $\mathbf{1 0 , 1 1 , 2 6 , 2 7}$ & 1.4 \\
\hline PROFILE 6 & NW-SE & 160 & & 1.8 \\
\hline
\end{tabular}

\section{Profile 1}

The profile 1 (SXY1) shown in Figure 9 (the residual map showing the profies) is a line drawn in the southwest-northeast direction in the western section of the study area. This section of the study area is characterised by low sedimentation..The profile is about $200 \mathrm{kmlong}$ it traverses sheets number 48 (Zogirma), sheet no.72 (Giru), sheet no.96 (Shanga), and sheet no.119(Chifu).A maximum thickness of sedimentation observed on this profile is $0.85 \mathrm{~km}$ around Giru and Shanga. The sedimentation shows a gradual decrease southeast.There is a wide area of relatively higher sedimentaion observed around shanga on the profile model.

\section{Profile2}

The profile 2 shown in Figure 9 is approximatetly $210 \mathrm{~km}$ long is drawn the southwest-northeast direction in the middle section of the study area . It passes through Sakkwabe (8), Lema (28), Tambuwal (50) and Gummi (51). Areas of highest sedimention thickness of $2.7 \mathrm{~km}$ is encountered on this profile around the on sheet no. 28 ( Argungu).This is the area of highest sedimentation obtained from 2D modeling. 


\section{Profile 3}

Profile 3 shown in Figure 9 is approximatetly $180 \mathrm{~km}$ long, is drawn southwest-northeast direction. This profile passes through Binji (9), Sokoto (10), Dange ( 29), and Ankah (52). The maximum sedimentaion thickness of $1.6 \mathrm{~km}$ observed on this profile is the viccinity of sheet no. 10 (Sokoto). The basement is almost at the surface around Dange town.

\section{Profile 4}

The profile 4 is shown on Figure9. The profile tranverses the study area diagonally starting from Kamba (71), Birnin kebbi (49), Tambuwal (50), Argungu (28), Dange (29), Rabah (11), and Isa (12). It is the longest profile of length of approximtely $400 \mathrm{~km}$. the sedimentation observed in this model is generally less than $1.0 \mathrm{~km}$ except few depressions were 1.2 thickness in sedimentation is observed.The maximum thickness of $1.2 \mathrm{~km}$ encountered on this model profile occurs around Argungu and Tambuwal with several undulations scattered along the profile.

\section{Profile 5}

This profile is approximately $300 \mathrm{~km}$ long and passes through Kangiwa (26), Lema (27), Sokoto (10) and Rabah (11). The profile (SXY5) shown in Figure 4.17 (the residual map showing the profies) The basement or a heavy intrusion is almost at the surface in the northwest section of the profile.A maximum sedimentary thickness of $1.4 \mathrm{~km}$ is encountered around Rabah (sheet no.11).

\section{Profile 6}

Profile 6 is about $160 \mathrm{~km}$ long and transvereses from Rabah to Mafara as shown on Figure 9. The sedimented thickness of $1.8 \mathrm{~km}$ is observed in the extreme northwest bordering with Niger republic. Another portion of sedimentary thickness of approximately $2.2 \mathrm{~km}$ at the middle around Isah and Rabah areas on sheets no. 11 and 12 respectively. A big intrusion at the extreme north-east is observed.The results of this profile model shown on Figure 9agrees very well with the results of the spectral depth analysis. The upward continuation map at $15 \mathrm{~km}$ qualitatively mapped out Isah and Rabah areas of the sokoto sedimentary basin as having the highest sedimentation in the whole area.

\section{Conclusions}

The conclusion to be drawn from this work, based on modeling of the residual magnetic anomalies identified on the residual magnetic intensity map of Sokoto sedimentary Basin are as follow:

From this study, results of the 2D Modeling carried out on the residual magnetic anomaly map encountered a maximum depth of $2.70 \mathrm{~km}$ in the vicinities of Argungu on profile 2. Depths of $1.67 \mathrm{~km}, 1.60 \mathrm{~km}, 2.50 \mathrm{~km}$ and $1.42 \mathrm{~km}$ are observed on profilesno.1,no.3, no 4, and no 5 respectively. The result collaborates well with those obtained by other researchers that conducted studies in some sections of the basin; notably among these, are results of studies by Umego (1990), Adetona et Al.,( 2007), Uwah (1984),Ayuba et al., (1999) and Udensi (2013).

Several depressions or variations in thickness have been observed in some parts of the Sokoto Basin, particularly around Argungu ,Isah, Rabah and Gandi areas, These deeper sections of the Sokoto sedimentary basin identified in this study, might be probable potential sites for hydrocarbon deposits and is therefore recommended to be subjected to further investigation.

\section{References}

[1]. Adetona, A.A.,Udensi, E.E and Agelaga, A.G. (2007), Determination of depth to buried magnetic rocks under the lower Sokoto basin using aeromagnetic data. Nigerian Journal of physics Vol.19 (2), Pp 275-283.

[2]. Ayuba,B.H. (1999), A three dimensional interpretation of aeromagnetic Anomaly near Dange village, Sokoto State Nigeria. Unpublish MSc Thesis. Physics Department Ahmadu Bello University Zaria, Nigeria.

[3]. Corell, L. and Grouch, V.J.S. (1985), Mapping basement zones from magnetic data in the san juan basin; New Mexico: presented at the $52^{\text {nd }}$ Annual International Meeting, Society or exploration, geophysicists, Dallas U.S.A.

[4]. Dobrin, M.B. (1976), Introduction to Geophysical Prospecting. Mc-Graw Hill Books Co (3 ${ }^{\text {rd }}$ Ed.) N.Y. Pp. 630

[5]. Ishaq,Y.and Udensi,E.E.(2010), Estimation of the sedimentary thickness in the Northern part of Sokoto Basin, Nigeria. Using aeromagnetic data.

[6]. Kearey, P, Brooks, M. and Hill, I. (2004), An Introduction to Geophysical Exploration. Third• Edition, Blackwell Pub.

[7]. Nigerian Geology Survey Agency,(1976), Geology Map of Nigeria. Scale1:2,00 000. Geology Survey of Nigeria, Kaduna, Nigeria

[8]. Oasis Montaj software inc.

[9]. Reeves, C. ( 2005);Aeromagnetic Surveys; Principles, Practice and Interpretation, Training Programme, NGSA, Nigeria

[10]. Reynolds, J.M. (1990): An introduction to applied and environmental Geophysics, John Willey and sons Limited Pp 116 - 207.

[11]. Shehu, A.T.,Udensi, E.E, Adeniyi,J.O and Jonah, S.A.(2004),Spectral Analysis of Magnetic Residual anomalies over the upper Sokoto Basin, Nigeria. Zuma Journal of pure and Applied Science,Vol.6(2) Pp 37-49.

[12]. Surfer (R) version 8.012002 Golden software inc.

[13]. Spector, A. (1968),Spectral analysis of aeromagnetic data. Ph.D Thesis,University of Toronto, Canada. 
[14]. Spector, A., and Grant, F.S. (1970), Statistical Models for interpreting aeromagnetic data. Geophysics Vol.(.35), Pp.293-302.

[15]. Umego,M. (1990),Structural interpretation of gravity and Aeromagnetic Anomalies over Sokoto Basin, north' Western Nigeria. Unpublished PhD Thesis,Department of Physics, Ahmadu Bello University, Zaria, Nigeria.

[16]. Uwah, EJ.(1984), Investigation of radiometric anomalies by nuclear and other methods; A case study of Sokoto Basin of Nigeria. Unpublished Ph.D Thesis. Ahmadu Bello University Zaria. Nigeria

[17]. Udensi,E.E.,(2013),Subduing the Earth with Exploration Geophysics; My contribution, Inaugural Lecture series No.24 of Federal University of Technology, Minna. 